derive updated reference equations for lung function" [1]. The latter appears to be the central issue raised by P. Degens and R. Merget with regard to the article [1]. The authors state that it is not necessary to move on with the European project as updated equation references already exist [2]. This is where we are compelled to disagree.

Apart from the fact that the Swiss Cohort Study on Air Pollution and Lung Diseases in Adults (SAPALDIA) was cited along with many others in table 1 of the article [1], we are not convinced that a study conceived to derive only simple spirometric parameters, in a limited central European area and over a modest lifespan, could qualify as a comprehensive set of references for a continent. While it is important to appreciate the scientific level of the SAPALDIA, which meets standard methodological, epidemiological and statistical criteria, we believe that the new European references should include not only spirometry but also lung volumes, diffusing lung capacity for carbon monoxide and perhaps other tests, all possibly derived from the same subjects; it should cover most of the countries, and expand the lifespan as much as possible owing to the continuous ageing forecast.

With this in mind, and in the same way as many other national studies conducted in Europe over recent years that are listed in American Thoracic Society/European Respiratory Society document, the Swiss Cohort Study on Air Pollution and Lung Diseases in Adults reinforces the need for periodically updating the reference values. While waiting for the possibility to perform a new pan-European study, perhaps through a pool of private and public grants, the availability of the Swiss Cohort Study on Air Pollution and Lung Diseases in Adults reference values will certainly be of great help for the Swiss pulmonary function test laboratories.

\section{R. Pellegrino*, G. Viegi", P. Levy ${ }^{\oplus}$ and V. Brusasco ${ }^{+}$}

*Azienda Ospedaliera Santa Croce e Carle, Cuneo, ${ }^{\#}$ CNR Institute of Clinical Physiology, Pisa, and Internal Medicine Dept, Faculty of Medicine and Surgery, University of Genova, Genova, Italy. 'Sleep and Respiration Unit, CHU Grenoble, Grenoble, France.

\section{STATEMENT OF INTEREST}

None declared.

\section{REFERENCES}

1 Pellegrino R, Viegi G, Brusasco V, et al. Interpretative strategies for lung function tests. Eur Respir J 2005; 26: 948-968.

2 Brändli O, Schindler C, Künzli N, Keller R, Perruchoud AP. Lung function in healthy never smoking adults: reference values and lower limits of normal of a Swiss population. Thorax 1996; 51: 277-283.

\title{
Smoking: leading by example?
}

\section{To the Editors:}

"Smoking kills", "Smoking seriously harms the health of you and others around you" and "Smoking clogs the arteries and causes heart attacks and strokes" are among the statements now seen frequently on the packaging of tobacco products in the UK, such statements having become a legal requirement in 2003. Following a recent UK directive, cigarette packages will carry picture warnings by the end of 2008 [1]. No one can argue that smoking is not bad for health. The effects on health of smoking remain a topical issue as more and more countries ban smoking in all enclosed public places and workplaces.

England became smoke-free in July 2007, following the lead of other countries such as Ireland, Italy, Malta, Norway, Sweden and Scotland, who have all banned smoking in enclosed public places. France has introduced some restrictions and plans to impose a complete ban in January 2008. The USA has a ban in some states and India plans to introduce smoke-free public buildings in its capital by 2009 [2, 3].

Respiratory physicians, as a group, have played a large part in advocating this ban, with groups such as the British Thoracic Society Tobacco Committee forming to discuss action plans. Indeed, at the 2007 European Respiratory Society (ERS)
Congress, there were over 200 presentations and posters containing "smok" (i.e. the terms smoke, smoking or smoker) in the title, and many more on the topic of smoke and smokerelated health problems, not including these words in the title [4].

We were therefore surprised, no, shocked to see such a large number of ERS congress delegates smoking. The expression "do as I say, not as I do" is widely known in the UK. Although it is difficult to contest the presumption that everyone, even respiratory doctors, have a right to do as they wish, the inherent contradictions of respiratory physicians knowingly damaging their own lungs and the health of those around them remains stark.

At the recent ERS Congress, with delegates wearing easily recognisable Congress badges and blue rucksacks seen all over Stockholm (Sweden), such hypocrisy must have been puzzling to the average Swedish bystander.

How can we ever expect the public to listen to what is said about the harm of smoking and take note when they can see that we as a group of professionals are not heeding our own advice? So, a plea to all those attending future congresses: if you must smoke, at the very least anonymise yourself first! 
R. Thursfield* and S. Brown ${ }^{\#}$

*Whipps Cross University Hospital, London, and "Hillingdon Hospital, Uxbridge, UK.

\section{STATEMENT OF INTEREST}

None declared.

\section{REFERENCES}

1 Department of Health. Regulating Tobacco Products. www. dh.gov.uk/en/policyandguidance/HealthandSocialCare Topics/tobacco/DH_4083845. Date last updated: August 30, 2007. Date last accessed: October 10, 2007.
2 Anon. Delhi govt considering steps to make capital smokefree. The Times of India http:/ /timesofindia.indiatimes.com/ articleshow/2402778.cms. Date last updated: September 25, 2007. Date last accessed: October 10, 2007.

3 SmokeFreeWorld ${ }_{\mathbb{B}}$ WwW.smokefreeworld.com. Date last updated: September 11, 2007. Date last accessed: October 10, 2007.

4 European Respiratory Society. Stockholm 2007 ERS Annual Congress Online Scientific Programme. www.ersnetsecure. $\mathrm{org} / \mathrm{public} / \mathrm{prg}$ _congres.entree?ww_i_congres $=68$. Date last updated: September 15, 2007. Date last accessed: September 25, 2007. 